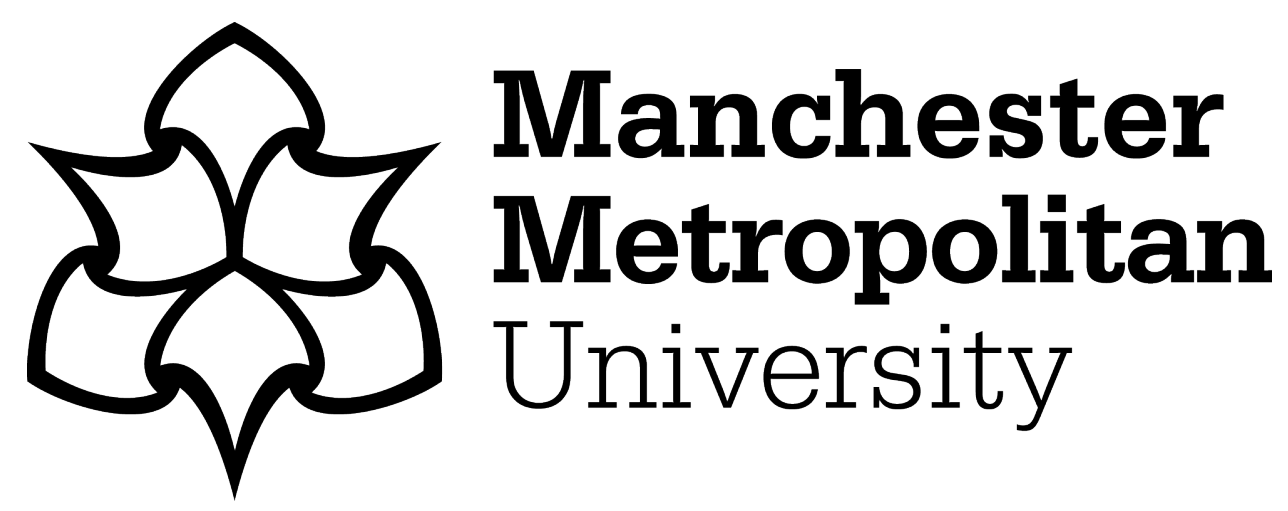

Gray, P ORCID logoORCID: https://orcid.org/0000-0002-1546-9333 and Fraser, P (2005) Housing and heroin use: The role of floating support. Drugs: Education, Prevention and Policy, 12 (4). pp. 269-278. ISSN 0968-7637

Downloaded from: https://e-space.mmu.ac.uk/617311/

Publisher: Taylor \& Francis

DOI: https://doi.org/10.1080/09687630500049684

Please cite the published version 


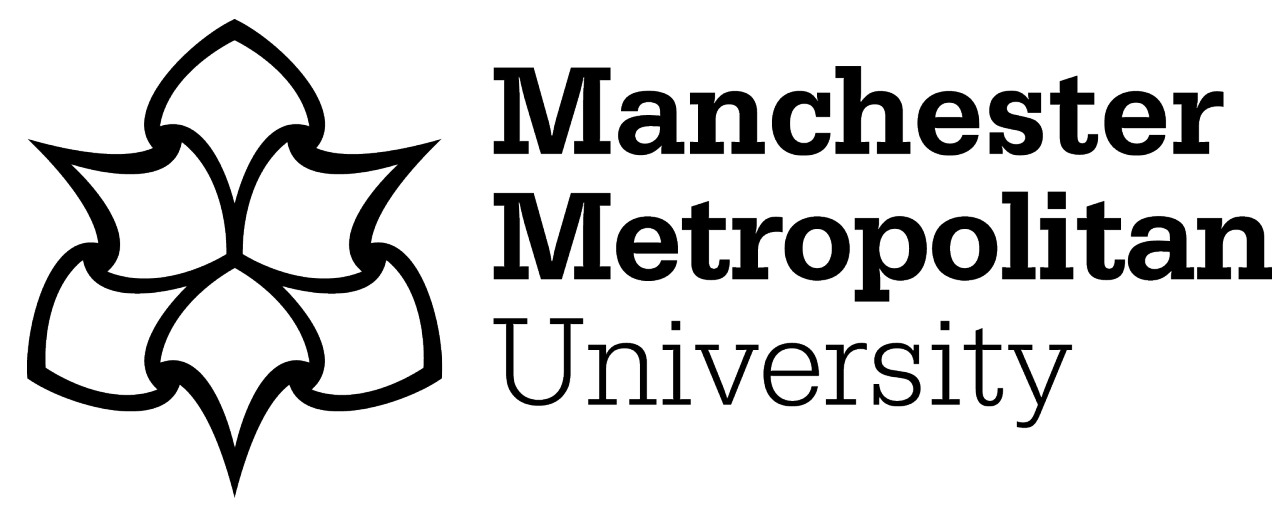

Gray, P and Fraser, P (2005)Housing and heroin use: The role of floating support. Drugs: Education, Prevention and Policy, 12 (4). pp. 269-278. ISSN 0968-7637

Downloaded from: http://e-space.mmu.ac.uk/617311/

Version: Accepted Version

Publisher: Taylor \& Francis

DOI: https://doi.org/10.1080/09687630500049684

Please cite the published version 


\title{
Housing and heroin use: The role of floating support
}

\author{
PAUL GRAY ${ }^{1}, \&$ PENNY FRASER ${ }^{2}$ \\ ${ }^{1}$ Department of Criminology, Keele University, Staffordshire, UK, and ${ }^{2}$ Former Research and \\ Evaluation Manager, Nacro, UK
}

\begin{abstract}
This article is based upon interviews with heroin users and explores the interaction between housing circumstance and heroin use. It looks primarily at the role that floating support schemes can play in helping heroin users to acquire stable housing, and more importantly, to keep it. This stability then provides an opportunity for those heroin users who want to address their drug problems to do so. In addition to focusing on floating support, this article also looks at: the impact of being homeless on heroin use; whether housing circumstance affects the ability to reduce dependence on heroin; and the issues heroin users face in accessing stable housing. The discussion section highlights a number of key areas that need to be addressed if the housing requirements of heroin users are to be met. These include: increased information about housing options; increased availability of preventive packages of support for those who have not entered the criminal justice system; and increased partnership working between different housing support schemes and housing providers.
\end{abstract}

\section{Introduction}

This article is based upon interviews with heroin users and explores the interaction between housing circumstance and heroin use [1]. The interviews were conducted as part of a larger Home Office-funded study undertaken by the authors during 2003 [2]. The focus of the study was to examine the impact of floating support [3] on the lifestyles of problematic drug users, or those at risk of misusing drugs, and to identify and disseminate elements of good practice in the planning and implementation of schemes. The study was conducted at three separate sites across the country and focused on three projects providing floating support to drug users in independent housing. These projects were part-funded by the Communities Against Drugs Programme, which gave local Crime and Disorder Reduction Partnerships, Drug Action Teams, and the police the opportunity to bid for funds to support efforts to disrupt local drugs markets and reduce the harm caused to communities by drugs.

Correspondence: Paul Gray, Department of Criminology, Keele University, Staffordshire ST5 5BG, UK. Tel: +44 (0)1782 583934. E-mail: p.m.gray@crim.keele.ac.uk 
In this article we focus on just one of the three sites from the original study [4]. This is because the clients who received the floating support at this site were primarily heroin users [5]. After a brief literature review and methodology, we look at: the characteristics of the sample; the impact of being homeless on heroin use; whether housing circumstance affects the ability to reduce dependence on heroin; and the issues heroin users face in accessing stable housing; before focusing on the role that floating support schemes can play in helping heroin users to acquire stable housing and, more importantly, to keep it. The discussion identifies the need for: increased information for heroin users about their housing options; increased availability of preventive packages of support for homeless heroin users who have not entered the criminal justice system as well as those who have; and increased partnership working between different housing support schemes and housing providers to ensure an overlap of support.

\section{Housing and drug use}

Research has found that homelessness and drug use are closely linked. One study found that four out of five homeless people were regular drug users, with almost half having used heroin or crack in the last month (Fountain \& Howes, 2002; see also Wincup, Buckland \& Bayliss, 2003). The lack of a stable home can also make it difficult to access or keep appointments with treatment services or other medical help (Reid \& Klee, 1999; Nwakeze, Magura, Rosenblum \& Joseph, 2003), leading to an increased use of emergency services (Palepu et al., 2001; Kushel, Perry, Bangsberg, Clark \& Moss, 2002). Indeed research has noted the chronic difficulties of improving treatment outcomes unless basic needs such as accommodation are addressed (Haracopos, Dennis, Turnbull, Parsons \& Hough, 2003).

Drug use (along with violence and extreme antisocial habits) is also a factor in exclusion from social housing (Fakhoury, Murray, Shepherd \& Priebe, 2002). Although the Homelessness Act of 2002 includes an extension of the category of 'priority need for housing' to new groups of vulnerable homeless people, drug users are not listed as a specific category. For example, local authorities will not necessarily accept problematic drug use, even of a severe and chaotic kind, as a reason for classing a homeless person as vulnerable.

The overlap between problem drug use and crime (Bennett \& Holloway, 2004) inevitably means a crossover between housing agencies and the criminal justice system. It is a consistent finding that the housing needs of many prisoners intensify while in prison and at the point of release (Walmsley, Howard \& White, 1992; HMIPP, 2001). The expressed needs of problematic drug users in prison frequently include a need for housing on release; the implication being that treatment alone will not suffice to meet the needs of prisoners at release (Alemagno, 2001). Moreover, if ex-offenders return to familiar locations, this can re-stimulate drug habits and offending (Travis, Solomon \& Waul, 2001; Carnaby, 1998).

\section{Methodology}

As mentioned in the introduction, this article focuses on just one of the three sites from the larger Home Office study. It is based primarily on interviews with the project clients at that site. It also uses material from interviews with a comparison group of other heroin users, who were not in receipt of floating support, but were otherwise matched in terms of age, drug use, engagement in treatment and history of housing need [6].

Both the project and comparison group clients were interviewed up to three times over the six-month fieldwork period, using a standardized schedule [7]. The interviews also 
incorporated a 'life-events calendar' [8] to prompt memories across a period of over two years, thus allowing examination of the temporal sequencing of different aspects of the clients' lives (e.g. housing, drug use, treatment, employment, etc.), and to help us understand associations between these factors over time [9].

\section{Characteristics of the sample}

The age of the 18 heroin users on which this article is based ranged from 21 to 36, with the average age being 29 [10]. All but three of the sample were male. Homelessness and housing instability were long-term recurrent problems for the sample, and were frequently related directly to their drug use. Indeed, between 2001 and 2003, and prior to receiving floating support, eight of the 12 project clients had become homeless as a result of their drug use, either directly (i.e. through eviction or rent arrears) or through relationships breaking down (i.e. with family, friends or partners). Most had lived in squats, on the streets, in hostels of various kinds, and in prison. Few of the 12 project clients had ever had their own tenancy before being housed with the project. All of the sample had long heroin-using careers, which mainly started when they were in their late teens or early twenties and came on the back of heavy consumption of other recreational drugs and alcohol.

The family backgrounds of many of the sample included parental alcoholism and in some cases parental drug use. There was widespread evidence of abuse, family criminality and experience of premature bereavement. Many had on-going or recent experience of mental health difficulties, including suicide attempts and depressive illnesses. All but four of the sample had commenced a treatment programme involving methadone maintenance.

\section{Impact on heroin use of being homeless or losing housing}

A number of clients made a similar point about the relationship between their consumption of heroin and rough sleeping.

I had various attempts [to come off heroin] ... when I was in a hostel, not on the streets. When I was on the streets you just take drugs because it is the only way to sleep. (John [11], aged 29, comparison group client.)

Even when not sleeping rough, one of the project clients found that when he previously lost his home he was obliged to move to a different part of the country (i.e. back to where his parents lived), in order to have support and a roof over his head. Moving to a different area usually results in an interruption in treatment for heroin use as GPs will no longer prescribe unless the prescription can be picked up in person. Consequently, patients then have to apply for treatment in the new area, and in the ensuing delay will probably score illegal drugs to tide them over. All of this can be detrimental to motivation and capacity to resume treatment.

All of the sample had previously had opportunities to come off heroin. Many had experienced spells in prison, where they had detoxified with Subutex ${ }^{\circledR}$; others had been in residential rehabilitation; and others had undergone some form of home detoxification. However, each of those, who at some point over the preceding two years had been released from an institutional setting in which they received some treatment for their drug addiction, had started using heroin again within two months of release. In not one case had they had stable housing on leaving prison or residential rehabilitation. Some had found 
unsuitable lodgings with other drug users, while others had moved back to parents or other relationship-linked housing that was not stable.

This lack of stable housing had affected the clients' ability to access treatment or aftercare; and these two factors-lack of a stable home and lack of treatment or services for those who may be clean but at high risk of relapse-had interacted to increase the risk of heroin use within a short time of release. The following exchange illustrates this point well:

INTERVIEWER: Did you find it hard not using drugs in rehab?

TONY [aged 27, project client]: Not really.

INTERVIEWER: But when you came out?

TONY: I was on drugs straight away ... I couldn't manage on my own.

For one of the comparison group clients, her attempts to maintain her abstinence from heroin were threatened by having no alternative to living with her boyfriend, who had not 'kept to his side of the bargain' and was still engaged in heavy use of crack and heroin.

He is just throwing it in my face every day and night. I have been trying to spend as much time away from home as possible. I am quite a strong individual ... if I had my own place I would feel a lot more secure. If I could get away from him it would stop me getting the smack and crack in my face all of the time. [I could] build up my own life, move on and get a job. (Paula, aged 25, comparison group client.)

\section{How does housing circumstance affect ability to reduce dependence on heroin?}

Although the sample reported using a range of techniques to stop using heroin, their housing circumstances affected their capacity to do so. Many of them said that staying away from other users was significant and that this could be difficult in a hostel, especially where rooms are often shared.

\section{INTERVIEWER: Were you trying to come off drugs at that point?}

JOHN [comparison group client]: Yes. I didn't do too bad. I reduced on methadone, I went on to Subutex, but because it was hostel life it was difficult.

Staying away from other users can be easier when you have your own place as you can shut the door and not contact anyone. However, this requires considerable resolve, as it can also be easier to have other drug users use with you in your own flat rather than in the less safe/amenable conditions of the street. Some of the sample said that not telling anyone where you live is clearly easier when you have your own flat. Choosing to tell people where you live is then within your control, unlike situations where you live with other people who have the capacity to allow other drug users/dealers to visit the property. In addition to enabling heroin users to reduce their dependency on heroin, having a stable home could also increase a person's stake in leading a crime-free lifestyle.

INTERVIEWER: Has it made any difference ... having a stable place to live?

MARK [aged 28, project client]: Less prone to getting into trouble. Before I would think I am only living in a bedsit and nothing in there is mine and I could easily go on the run from the police ... and not be worried about it. Whereas now if I get into trouble I am going to lose my flat, lose all my stuff, which I have collected, TV, video. It is not worth getting into trouble nowadays. 


\section{Issues for heroin users in accessing stable housing}

The interviews revealed a range of reasons why heroin users fail to acquire stable housing. These included not caring about where you live, with whom you live, or how your accommodation is sustained while you are in the throes of drug addiction.

I was taking drugs and I didn't really care. I wasn't looking after myself and I didn't care about the consequences.

Then you look around you one day and say 'I don't want this' and you try to do something about it. (Nick, aged

33, project client.)

Until their late twenties or thirties, many of the sample had either lived in, or returned periodically to, the family home during times of housing crisis. These stays with family had often broken down due to the respondent's drug use.

\footnotetext{
Not many of my family will help me any more, that is why I ended up the way I did, in squats, on the streets, with friends. (Nick, project client.)
}

INTERVIEWER: What happened to make you homeless?

TOM [aged 26, project client]: I didn't want to put my parents through any more stress so I moved away from there.

The majority of the sample commented that they had found it difficult to access housing, or support and advice about housing, without being referred by an agency of the criminal justice system. The reasons cited were: arrears from previous tenancies; perceived prejudice against them as drug users; lack of information about available housing options; or the presumption that, as low priority cases, they would be housed in other parts of the county, far from centrally-located drugs services upon which they depended on a daily basis.

INTERVIEWER: Had you ever thought about moving into a hostel?

NICK [project client]: Yes but there was no-one to point me in that direction ... I tried [the local branch of a national housing advice agency]. They looked in their book and said 'drug user-he will be a problem'. There was nowhere else.

INTERVIEWER: Had you ever thought about looking for a hostel before?

DAVE [aged 27, project client]: No I hadn't. I wasn't aware that they were around. Nobody tells you about them. It is really strange, unless you go through the judicial system there is actually nobody that you can go and see.

This is where specialist housing support projects can play a vital role. They can advocate on behalf of prospective tenants with housing providers. For example, they can help agree an arrears repayment plan while a housing applicant is in temporary accommodation and on the council waiting list. Providing this assistance, and the assurance of further support when an applicant is housed, can help heroin users access and maintain the stable housing that they need.

A package of support, that followed a meeting with an Arrest Referral Worker while in police custody after an arrest, was cited by many of the sample as the best example that they had come across of all the relevant agencies working together to meet their linked needs of offending, drug use and housing.

INTERVIEWER: How did you find out about the [supported housing] project?

KEVIN [aged 34, project client]: Through the Arrest Referral ... I felt a bit rough, I was in the police station, I got contacted and went in to see them and they were really helpful. 


\section{Others cited being put on a Community Rehabilitation Order (CRO) or Drug Treatment and Testing Order (DTTO).}

Within a day of being on the CRO the housing officer at probation brought me straight down here and I had an assessment, and from here she took me to [an organization that runs hostels aimed at offenders and drug users in the area] and I had an assessment with them and was housed within three days. Without [the CRO] I wouldn't be where I am now. It has been really helpful. From the instant I got the order I have had all the support and help I could ever wish for... If you make an effort and show willing then they will go to lengths for you, such as with housing. (Dave, project client.)

\section{The role of floating support}

A number of the sample described the strength of resolve and character that is required when coming off heroin, because you are forced to acknowledge aspects of yourself, your life and your behaviour that have suppressed while you have been an addict. To do this without close personal support and advice is a major challenge, and specialist supported housing can help with this in a way that treatment and counselling alone often cannot.

When you stop using quite a lot of your suppressed feelings and emotions start coming back again ... When you take drugs you live in a different universe to everybody else and you feel different to everybody else, your priorities are different to everybody else. So coming to terms with that, and learning to cope with that, is the most difficult thing. (Luke, aged 31, project client.)

You do need a hell of a lot of support when you come off heroin, because all you tend to do is knock yourself and look back at your past. If you have any conscience at all you can be really quite embarrassed about your past, to look at the mess and entangled life that you have left behind. How do I sort this out? It is at times like that that people actually need the support, in order to take it one step at a time. (Kevin, project client.)

Floating support projects, like the one that our project clients were involved with, have the flexibility to provide pre-tenancy support to potential tenants. This helps prepare them for the responsibility of running their own home-something many have not previously experienced. It also helps to establish a relationship between the floating support worker and the tenant, such that the support is valued by the tenant as much as the accommodation itself. This helps avert situations where tenants use the project as a means of securing independent accommodation and subsequently ignore appointments with the floating support worker. Pre-tenancy support is particularly effective when delivered to a prospective tenant who is occupying a temporary place in a hostel.

INTERVIEWER: Can I ask you a bit about how you managed to get clean. Is that while you were living at the hostel?

NICK [project client]: Yes. I knew I was getting a house.

INTERVIEWER: Did that give you an incentive?

NICK: Yes, I had so many people fighting for me.

INTERVIEWER: Did you get support from the hostel?

NICK: Well, it was mainly the [floating support] worker.

One of the difficulties often cited by heroin users trying to reduce their use of drugs is that the neighbourhood they are living in is not conducive to this.

If you are plonked in the middle of somewhere that is full of drug dealers, then that is not good ... it is asking for trouble big time, because there are so many dealers. (Matthew, aged 30, comparison group client.) 
It is just where I am living, it is a nightmare. There are drug dealers living in the building. There are about twenty people who hang around near the shops all night or during the day when you are going out, or on the weekend. There is a lot of gear, it is always in your face. (Mark, project client.)

As members of a Sensitive Lettings Policy group, the floating support project in this study had a pre-tenancy role in helping to decide the most appropriate location for housing their clients. The project also supported those living on estates or districts where there was drug activity, by helping them to devise and maintain strategies to avoid the temptation to buy drugs, or the harassment from proactive drug dealers. In addition, by helping heroin users to maintain probationary or introductory tenancies and attain a secure tenancy, the project helped heroin users, living in estates where there were drug dealers, to get to a position where they could apply for a transfer.

I have been with [the project] for twelve months, so I will have a secure tenancy hopefully within the next few days. Instead of just getting a mutual exchange I should be able to get a transfer, hopefully. (Mark, project client.)

For the project clients in receipt of floating support, the introductory or probationary tenancy, with the council or housing associations, was the first time that they had been a tenant with their own home, despite most being in their late twenties. The responsibility could often be daunting, and without the availability of housing support, they would not have sustained the tenancy.

At one point I went back on the streets for a couple of weeks because it is just that I have never had it before, never had to pay my own bills and fill up my fridge with food and simple things like that. I have never done it before; I have always lived within the rules. It is like me saying 'Give me the rules and I will be all right and I will be able to cope', but to have to do it all myself, well, at one point, it became a bit much. At the moment I am managing to cope a lot better, but it is not easy, because I am learning all this at an older age. (Steve, aged 27, project client.)

[The floating support] really does help, because when you first move in you are at a very fragile state in your life, and it is very easy to let loads of drug using friends come round and then their friends. And you'll have people dossing on your floor ... and that's something you've got to avoid. So basically you do need that regular contact. (Mike, aged 30, project client.)

Floating support projects can also reassure housing providers about the progress that their tenants are making towards stability and independence. Without this reassurance, providers may be reluctant to offer tenants secure tenancies, resulting in the floating support projects 'silting-up', and being unable to take on new clients.

\section{Discussion: Meeting the housing needs of heroin users}

As a result of their drug use, many heroin users lose their home. The main ways in which this had come about for our sample was: because the heroin use had put an intolerable strain on their family and they had been asked to leave; because they had gone to prison; or because they had defaulted on rent or mortgage payments. However, most had never really had their own home in the sense of being a tenant or home-owner. For a large part of their adult lives they had 'got by' with an itinerant lifestyle, involving rough sleeping, periods abroad, 'sofa surfing' with friends and family, short periods of subletting from friends, and spells in custody. They had experienced a lack of information about their housing options as heroin users (with considerable support needs), and were unsure of the wisdom of declaring their drug needs to housing providers.

Arrest Referral, Drug Treatment and Testing Orders, and Community Rehabilitation Orders offer heroin users the prospect of being able to tackle their drug use at the same time as getting help with housing and other social needs. Against this backdrop, surely 
one of the key challenges for tier one and two services under the Department of Health's 'Models of Care' framework for substance misusers (including housing and other non-substance-specific services for drug users), is how to enable vulnerable homeless heroin users to access similar packages before they get arrested. In other words, there is a need to increase the availability of preventive packages of support for heroin users who are homeless but not yet committing crime, or who are committing crime but have not yet been arrested. Access to a similar package of support, from day one of release, is also needed for heroin users leaving prison or residential rehabilitation [12].

The location of housing can make a difference to whether initial motivation to change can be sustained by heroin users. Being housed on an estate where drug dealers are active can make it harder for someone to maintain their motivation (Rutter, 1994; Haracopos et al., 2003). So, for many recovering heroin users, housing in areas away from former drug associates and dealers will be the most appropriate. However, for others, this strategy may increase a drug user's physical and social isolation from services, family and friends. Housing support schemes and housing providers need to work together to ensure that the individual needs of clients are taken into account.

Housing support schemes and providers also need to work together to develop further the potential for floating support workers to assist tenants with personal strategies for reducing the risk of returning to drugs or offending now they are in their own homes (e.g. setting rules with friends about there being no drugs on the premises; direct discussions about what they would lose if they returned to offending; and what to do when craving drugs or needing money). This should include the examination of wider questions, such as availability and appropriateness of other forms of informal social support or 'control' for tenants, such as family, non-drug-using friends, and other pro-social networks (Cheung \& Cheung, 2003). There may be a need for housing support schemes to dedicate further resources into bolstering up these informal support systems.

The transition for homeless heroin users to supported introductory or probationary tenancies (from local authorities or housing associations) is most effective when preceded by an 'overlap in support' between hostels (where our project clients had been temporarily housed) and the floating support scheme. There is a need for effective planning between hostels and floating support schemes to maximize the benefits of the transition between the two types of support. There is also a need not only for an adequate supply of hostel places but also for sufficient funding for floating support workers to work with hostel tenants before they move in to their own house.

\section{Conclusion}

It should be emphasized that there is no quick-fix solution to the difficulties faced by many heroin users in establishing a settled existence, after a lifetime of multiple disadvantage, drug taking and offending. The primary role of floating support schemes, like the one discussed in this article, is to help heroin users obtain housing and, crucially, to help them keep it. Without this support, many of them would lose their homes, through their inability to manage their money and their drug use. By providing some stability in their lives, floating support projects provide an opportunity for those heroin users who want to address their drug use to do so.

Of course, there is no presumption that by housing heroin users, floating support schemes will automatically reduce their drug use, with some users who appear to be settling down well (in terms of housing stability) maintaining regular heroin use during their supported tenancies. However, if those with problem heroin use remain homeless, then even if they 
are motivated to change, the lack of stability, the difficulties in accessing treatment without a stable address, and in keeping away from other drug users, will reduce the likelihood that they will be able to sustain change over the long term.

\section{Notes}

[1] We gratefully acknowledge the contribution to the study, on which this article draws, of other members of the research team from Nacro (Dr Sam Wright, Dr Toby Seddon, Anna Clarke, Shilpa Patel and Richard Peake) as well as that of Dr Roger Grimshaw from the Centre for Crime and Justice Studies. We are particularly grateful for helpful comments from Sam Wright and Toby Seddon on an earlier draft of this article.

[2] The opinions expressed in this research article are in no way an official view of the Home Office; neither should they be considered an indication of Home Office policy.

[3] 'Floating support' has been defined by the Housing Corporation (Performance Standards, 1997) as 'The extra housing management services provided for a limited time in accommodation which is not supported housing'. Floating support services operate at 'the interstices between housing services and other welfare professions in order to overcome problems of inter-professional fissure' (Allen, 2003). They help negotiate access to housing for clients of probation, homeless advice agencies, mental health and drugs services. They also work as intermediaries 'between the welfare state and clients [to] ensure that, once re-housed, clients maintain contact with the welfare services that [can] help them to sustain independent living' (Allen, 2003).

[4] This article is based on interviews with 18 respondents from just one of the study sites who reported using heroin during the period 2001 to 2003.

[5] The clients accessing the floating support at the other two sites were much younger, and primarily demonstrating non-problematic use of recreational drugs.

[6] Accommodation profiles ranged from homeless to being housed in mainstream local authority housing.

[7] The standardized schedule covered basic demographic information and background risk factors, as well as offending and drug use profiles, health and health-risk behaviour, employment and relationships.

[8] The version developed for this project was specially designed after consultation with Dr Bonnie Mhlanga, of the Home Office Research Development and Statistics Department, who, in conjunction with BMRB has pioneered the method in the UK (see Lewis \& Mhlanga, 2001).

[9] For the larger Home Office study, in addition to the interviews with clients, project staff also completed specially designed monitoring forms for each client, detailing the content and outcome of the housing support. These were completed on a monthly basis to produce a clear picture of precisely what was entailed in the housing-support work at each project, enabling us to model the support package at each project and contextualize each individual client's outcomes. Semi-structured interviews were conducted with the project staff and housing, drugs and other stakeholders at each site. Local homelessness and drugs policies were also reviewed.

[10] Of the 18 heroin users interviewed, 12 were project clients in receipt of floating support and six were comparison group clients.

[11] All respondents' names have been changed.

[12] The National Treatment Agency has announced that $£ 50$ million will be made available during 2004 to improve through-care and aftercare following treatment including for released offenders (press statement, 26 May 2004). 


\section{References}

Alemagno, S. A. (2001). Women in jail: Is substance abuse treatment enough? American fournal of Public Health, 91(5), 798-800.

Allen, C. (2003). On the logic of 'new' welfare practice: An ethnographic case study of the 'new welfare intermediaries'. Sociological Research Online, 8(1).

Bennett, T., \& Holloway, K. (2004). Drug use and offending: Summary results of the first two years of the NEW-ADAM Programme. Home Office Findings 179. London: Home Office.

Carnaby, H. (1998). Road to nowhere: A report on the housing and support needs of women leaving prison in Victoria. Melbourne: Flat Out Inc.

Cheung, Y. T., \& Cheung, N. (2003). Social capital and risk level of post treatment drug use: Implications for harm reduction among male treated addicts in Hong Kong. Addiction Research and Theory, 11(3), $145-162$.

Fakhoury, W. K. H., Murray, A., Shepherd, G., \& Priebe, S. (2002). Research in supported housing. Social Psychiatry and Psychiatric Epidemiology, 37(7), 301-315.

Fountain, J., \& Howes, S. (2002). Home and dry? Homelessness and substance use. London: Crisis.

Haracopos, A., Dennis, D., Turnbull, P. J., Parsons, J., \& Hough, M. (2003). On the rocks: A follow-up study of crack users in London. London: Criminal Policy Research Unit, South Bank University.

Housing Corporation (1997). Performance Standards for Registered Social Landlords (December 1997). London.

HMIPP (2001). Through the prison gate. A joint thematic review by HM Inspectorates of Prisons and Probation. London: Home Office (Her Majesty's Inspectorates of Prison and Probation).

Kushel, M. B., Perry, S., Bangsberg, D., Clark, R., \& Moss, A. R. (2002). Emergency department use among the homeless and marginally housed: Results from a community-based study. American fournal of Public Health, 92(5), 778-784.

Lewis, D., \& Mhlanga, B. (2001). A life of crime: The hidden truth about criminal activity. International fournal of Market Research, 43, 2.

Nwakeze, P. C., Magura, S., Rosenblum, A., \& Joseph, H. (2003). Homelessness, substance misuse, and access to public entitlements in a soup kitchen population. Substance Use and Misuse fournal, 38(3-6), 645-668.

Palepu, A., Tyndall, M. W., Leon, H., Muller, J., O’Shaughnessy, M. V., Schechter, M. T., \& Anis, A. H. (2001). Hospital utilization and costs in a cohort of injection drug users. Canadian Medical Association fournal, 165(4), 415-420.

Reid, P., \& Klee, H. (1999). Young homeless people and service provision. Health and Social Care in the Community, 7(1), 17-24.

Rutter, D. (1994). Keys to change: A study of the role of local authority housing in the care and rehabilitation of drug and alcohol users in the London Borough of Lambeth. DPI Paper 18. London: Home Office.

Travis, J., Solomon, A., \& Waul, M. (2001). From prison to home: The dimensions and consequences of prisoner re-entry. Washington, DC: The Urban Institute.

Walmsley, R., Howard, L., \& White, S. (1992). National Prison Survey 1991. Home Office Research Study 128. London: HMSO.

Wincup, E., Buckland, G., \& Bayliss, R. (2003). Youth homelessness and substance use: Report to the Drugs and Alcohol Research Unit. Home Office Research Study 191. London: HMSO. 